\title{
A PARTICIPAÇÃO FEMININA NA CONSTRUÇÃO DE UM PARLAMENTO DEMOCRÁTICO
}

\author{
Marilene Mendes Sow*
}

Resumo: Este artigo analisa a participação feminina na conquista da cidadania brasileira perante a Assembleia Constituinte de 1933 e a Assembleia Nacional Constituinte de 1987. Os dados foram coletados nos volumes do Diário do Congresso Nacional de 1933 e no portal do Congresso Nacional - Constituição 20 anos. Descreve o que foi consolidado como direitos para as mulheres. $\mathrm{O}$ estudo concluiu que há uma discrepância entre a norma constitucional vigente e as práticas sociais na realidade da mulher brasileira.

Palavras-chave: Mulher, Gênero, Política , Cidadania - Brasil

\begin{abstract}
This paper examines women's participation in the conquest of the Brazilian citizenship during the Constituent Assembly of 1933 and the National Constituent Assembly of 1987. Data were collected from the National Congress Gazette of 1933 and from the portal built to celebrate the 20th anniversary of the Constitution. Regarding women's rights, it is described what has been implemented. The conclusion is that in Brazil there is a discrepancy between the current constitutional acts and the reality of the social practices towards women.
\end{abstract}

Keywords: Woman, Gender, Politics, Citizenship - Brazil

\section{Introdução}

No ano de 2008 comemoramos os vinte anos da Constituição Cidadã, um marco na história política do nosso país. Com a Carta Magna de 1988 iniciou-se um período de Estado democrático, positivando-se vários direitos para o cidadão brasileiro, entre eles aqueles relativos

\footnotetext{
* Analista Legislativo da Câmara dos Deputados, atuando na Coordenação de Estudos Legislativos/Seção de Legislação Brasileira (marilene.sow@ camara.gov.br)
} 
à mulher, grupo de minoria ${ }^{1}$ que durante séculos permaneceu à margem da cidadania. Cidadania aqui conceituada como um conjunto de práticas jurídicas, políticas, econômicas e culturais, que define uma pessoa como membro competente da sociedade e que consequentemente molda $o$ fluxo de recursos para pessoas e grupos sociais (Tavolaro, 2008).

Somente com o movimento feminista no Brasil foi questionado o conceito patriarcal que destinava à mulher o cuidado doméstico, restrito ao lar, e a procriação. Entendemos o movimento feminista, segundo a definição de Teles (2008, p.12), em referência às ações de mulheres dispostas a combater a discriminação e a subalternidade feminina, buscando criar meios para que sejam protagonistas de sua vida e sua história.

No Brasil, as mulheres tiveram seu direito ao sufrágio garantido com o Decreto $\mathrm{n}$. 21.076, de 24 de fevereiro de 1932, que regulamentava o alistamento e o processo eleitoral no país. Era o novo Código Eleitoral do período pós-revolução de 1930, de Getúlio Vargas.

A representação feminina no Parlamento somente foi registrada no ano de 1933, com as eleições para a Assembleia Nacional Constituinte, cuja finalidade era a elaboração do texto da Constituição de 1934. Foi eleita pela Chapa Única de São Paulo a médica Carlota Pereira de Queiroz, que participou dos trabalhos da Assembleia Nacional Constituinte integrando a Comissão de Saúde e Educação. Dentro do Parlamento, coube-lhe uma tarefa árdua como pioneira na tribuna política: defender os interesses femininos, modificar a imagem domesticada da mulher, que passaria da vida familiar às atividades políticas, e lutar pela regulamentação dos dispositivos da legislação ordinária de acordo com os direitos e obrigações constitucionais das cidadãs. A despeito de seu esforço, a igualdade entre homens e mulheres em direitos e obrigações só foi contemplada na Constituição Federal de 1988, quando o movimento feminino já estava fortalecido. Havia várias entidades de defesa desses interesses que atuaram dentro do Congresso Nacional perante a Assembleia Nacional Constituinte de 1987. Dentre essas entidades, destaca-se o Conselho dos Direitos da Mulher, que, na figura de sua presidenta Jacqueline Pitanguy e vários outros nomes de mulheres intelectuais e ativistas políticas, elaborou uma Carta das Mulheres aos Constituintes e lançou a campanha "Constituinte pra valer tem que ter direitos da mulher" com o intuito de nortear as discussões e propostas femininas para o novo texto constitucional.

Diferentemente do que ocorrera no passado, na Assembleia Nacional Constituinte de 1987, já não era uma luta de uma única guerreira. A bancada feminina, alcunhada do "Lobby do Batom”, contava com 26 parlamentares que atuaram incessantemente na defesa dos direitos da

\footnotetext{
${ }^{1} \mathrm{O}$ conceito de minoria é tratado no texto, não sob o ponto de vista demográfico, em termos de número de população e sim, no aspecto sociológico no qual se define como um subgrupo existente dentro de uma sociedade que se considera e/ou é considerado diferente do grupo maior e/ou dominante, em razão de características étnicas, religiosas, ou de língua, costumes, nacionalidade etc., e que, por essa razão, não tem os mesmos direitos e/ou as mesmas oportunidades que é alvo de discriminação ou preconceito. (Bouldon, 1973, p. 342).
} 
mulher, tais como licença maternidade de 120 dias, direito à posse da terra ao homem e à mulher, igualdade de direitos e de salários entre homem e mulher e garantia de mecanismos que coibissem a violência doméstica, entre outros. O resultado do trabalho dessas parlamentares pode ser observado na Constituição de 1988, que assegurou vários mecanismos de defesa dos direitos da mulher para que ela pudesse alcançar com dignidade o pleno exercício da cidadania.

\section{A conquista da cidadania pela mulher}

A palavra cidadania vem do latim civitas, "cidade", e corresponde ao conjunto de direitos e deveres aos quais um indivíduo está sujeito em relação à sociedade em que vive. $\mathrm{O}$ conceito de cidadania surgiu na Grécia Antiga e era utilizado para expressar o conjunto de direitos relativos ao cidadão na comunidade dentro da cidade (polis). Ressalte-se que não pertenciam à categoria de cidadãos os escravos, mulheres e estrangeiros, que eram relegados a um lugar à margem dos assuntos de interesse público. Destarte, entendia-se a cidadania como a qualidade do indivíduo pertencer a uma comunidade com todas as implicações decorrentes de se viver em uma sociedade.

No Brasil, durante o período colonial, os direitos políticos eram restritos aos homens conforme demanda o patriarcalismo, ou seja, a sociedade estava organizada de forma que o poder, as decisões e os privilégios estavam sempre nas mãos dos homens. Com o movimento da independência, não se percebeu mudança significativa que pudesse levar o tripé direitos civis, sociais e políticos em direção a um Estado de cidadania. Os escravos permaneciam cativos, os analfabetos não tinham direito ao voto e os direitos políticos estavam limitados aos ricos e letrados. Situava-se a mulher com o papel de esposa e mãe dos filhos legítimos do senhor. A Proclamação da República, em 1889, não produziu mudanças no quadro geral, e a Constituição Republicana de 1891, em seus preceitos, excluiu do sufrágio analfabetos, mulheres, mendigos, soldados e religiosos.

\subsection{Direito ao voto}

A conquista do direito de voto aos cidadãos foi lenta e precisou superar uma série de barreiras para se universalizar. A primeira barreira foi a econômica, da renda; a segunda, a barreira de gênero. Só muito lentamente as mulheres foram conquistando o direito de votar. Na sua luta, utilizaram-se da imprensa escrita para fazerem suas reivindicações e buscaram apoio político para concretizarem suas aspirações ao voto.

No Brasil, a primeira Constituição Política do Império do Brasil de 1824 preconizava em seu artigos 92 e 95

Art. 92. São excluídos de votar nas Assembléas Parochiaes. (...) 
V. Os que não tiverem de renda liquida annual cem mil réis por bens de raiz, industria, commercio, ou Empregos. (...)

Art. 95. Todos os que podem ser Eleitores, são hábeis para serem nomeados Deputados. Exceptuam-se

I. Os que não tiverem quatrocentos mil réis de renda liquida, na fórma dos

Arts. 92 e 94. (Brasil, 1824)

Observa-se que o fator renda excluía as mulheres da categoria de cidadãs com direito ao sufrágio. No Brasil Império, a população feminina não tinha acesso ao trabalho, por isso não tinha remuneração comprovada. Já a segunda Constituição da República dos Estados Unidos do Brasil de 1891 estabeleceu:

Art. 70. São eleitores os cidadãos maiores de 21 anos, que se alistarem na fórma da lei.

$\S 1^{\circ}$ Não podem alistar-se eleitores para as eleições federaes, ou para as dos Estados:

$\S 2^{\circ}$ São inelegíveis os cidadãos não alistáveis. (Brasil, 1891).

Percebe-se aqui a exigência da prestação do serviço militar para o exercício do voto que, para as mulheres da época, era classificado como voluntário, assim nota-se uma lacuna na legislação, ao relacionarmos com o artigo supracitado da Constituição. Se as mulheres podiam prestar o serviço militar, consequentemente, abrir-se-iam as portas da cidadania, ou seja, o direito de voto. $\mathrm{O}$ que realmente exigia era um ato normativo estabelecendo essa condição de voto para as mulheres, o que fez com que o presidente da Província do Rio Grande do Norte (cargo equivalente ao governador do Estado de hoje), Juvenal Lamartine, fizesse passar uma lei que permitia o direito de voto às mulheres. Em 1927, registraram-se as primeiras eleitoras, em abril de 1928, 15 mulheres votaram no Rio Grande do Norte. Contudo, a Comissão de Poderes do Senado Federal, no ano de 1928, ao analisar essas eleições, requereu em seu relatório a anulação de todos os votos que haviam sido dados às mulheres, sob a alegação da necessidade de uma lei federal a esse respeito, sendo assim esses votos não foram reconhecidos. Ainda assim, pode-se dizer que o Rio Grande do Norte foi o primeiro estado brasileiro no qual a mulher foi às urnas declarar o seu voto. As duas primeiras mulheres alistadas como eleitoras no Brasil foram as professoras Júlia Barbosa, de Natal, e Celina Vianna, de Mossoró (RN). Também, seria potiguar a primeira prefeita do Brasil, Alzira Teixeira Soriano, eleita no município de Lages, em 1928, pelo Partido Republicano Federal (Teles, 2003).

No ano de 1932, o Presidente Getúlio Vargas normatizou as eleições no Brasil, assinando o Decreto $\mathrm{n}^{\circ} 21.076$, de 24 de fevereiro de 1932, que regulamentava o alistamento e o processo eleitoral no país. Esse ato normativo assegurava o sufrágio universal e secreto, concedendo o direito de voto a todos os brasileiros maiores de 21 anos, alfabetizados e sem distinção de sexo; garantindo assim à mulher o direito de voto. Posteriormente, esse dispositivo foi incorporado à nova Constituição brasileira de 1934:

Art 108. São eleitores os brasileiros de um e de outro sexo, maiores de 18 annos, que se alistarem na fórma da lei. 
Paragrapho único. Não se podem alistar eleitores:

a) os que não saibam ler e escrever;

b) as praças de pré, salvo os sargentos, do Exército e da Armada e das forças auxiliares do Exército, bem como os alunos das escolas militares de ensino superior e os aspirantes a oficial;

c) os mendigos;

d) os que estiverem, temporária ou definitivamente, privados dos direitos políticos.

Art 109. O alistamento e o voto são obrigatórios para os homens e para as mulheres, quando estas exerçam funcção publica remunerada, sob as sancções e salvas as excepções que a lei determinar. (Brasil, 1934)

Terminava, assim, uma batalha de décadas. Reconhece-se o direito ao pleito e as mulheres passam a ter outros objetivos, como a posição no mercado de trabalho, proteção à maternidade e maior acesso à educação. A luta continuava em outros setores.

\section{A mulher e a política}

A participação das mulheres na arena política do Brasil ocorreu oficialmente no ano de 1933, na Assembleia Constituinte do mesmo período, com a eleição de Carlota Pereira de Queiroz. Com a chegada dessa segunda deputada federal, a bióloga e suplente Bertha Lutz, empossada devido à vaga deixada por um deputado federal, uniu forças para estabelecer uma comissão especial na Câmara dos Deputados com o propósito de redigir um Estatuto para Mulher, com o fim expresso de regulamentar os dispositivos da legislação ordinária de acordo com os direitos e obrigações constitucionais da cidadã (Diário do Poder Legislativo, 19101937).

Entre as reivindicações, destacam-se maior tempo de licença maternidade, mudanças jurídicas em benefício da mulher, principalmente a casada, creches e outras. No entanto, tais pedidos não chegaram a ser postos em prática. A igualdade entre homens e mulheres em direitos e obrigações só foi contemplada na Constituição de 1988.

\subsection{Assembleia Nacional Constituinte de 1933}

A Assembleia Nacional Constituinte iniciou seus trabalhos em 3 de maio de 1933 e promulgou a nova Constituição em 16 de julho de 1934, elegendo de imediato Getúlio Vargas para um mandato de quatro anos à frente da Presidência da República.

A proposta das feministas para a redação do anteprojeto de Constituição incluía treze itens. Enfatizava as questões diretamente vinculadas ao cotidiano das mulheres, como a maternidade e proteção à infância, e contemplava problemas que afetavam as condições de vida da população pobre como um todo. Pensando de forma ampla e com ousadia para a época, as feministas condenaram as diferenças salariais por sexo, nacionalidade ou estado civil, previram 
a instituição de licença maternidade remunerada, além de pleitearem o acesso irrestrito de mulheres a cargos públicos.

A participação de uma deputada constituinte foi de grande valia para a defesa desses itens. Ao subir à tribuna do dia 13 de maio de 1934, Carlota Pereira de Queiroz pronunciou :

Subo hoje à tribuna, para vencer mais uma etapa da nossa evolução política e iniciar definitivamente a vida activa da mulher parlamentar no Brasil. Além de representante feminina, única nesta Assembléia, sou, como todos os que aqui se encontram, uma brasileira, integrada nos destinos do seu paiz e identificada para sempre com os seus problemas (Queiroz, 1934, p.4).

Carlota Pereira de Queiroz nasceu em 13 de fevereiro de 1892, em São Paulo, e diplomou-se em Medicina no ano de 1926. Durante a chamada Revolução Constitucionalista, em 1932, em São Paulo, organizou uma frente de 700 mulheres para prestar assistência aos feridos desse movimento. Em 1933, foi eleita à Assembleia Nacional Constituinte pela Legenda Chapa Única por São Paulo Unido. A Federação dos Voluntários incluiu uma mulher na relação dos 22 candidatos da Chapa Única por São Paulo Unido. Na época, tanto o Partido Republicano Paulista (PRP) como o Partido Democrático (PD) estavam com suas principais lideranças paulistas exiladas; sendo assim, os partidos uniram-se em uma chapa única e elegeram 17 dos 22 candidatos integrantes da chapa. Carlota foi eleita com a votação de 5.311 e 176.916 votos em $1^{\circ}$ e $2^{\circ}$ turnos, respectivamente (Godinho, 1934, p. 209).

Eleita em 03 de maio de 1933 e empossada no mês de novembro do mesmo ano, Carlota participou dos trabalhos da Assembleia Nacional Constituinte, integrando a Comissão de Saúde e Educação ${ }^{2}$. Na Assembleia Constituinte, ela concentrou sua atenção na área social, onde defendeu os direitos da criança, apresentou projetos criando os serviços sociais e vinculando recursos orçamentários à assistência social.

Dentre as suas contribuições para o texto do anteprojeto da Constituinte de 1933 destacam-se:

1 A Emenda $n^{\circ} 690^{3}$ : Inclui a assistência social no artigo 125 do anteprojeto, que se positivou como o artigo 138 do texto constitucional de 1934, e assim pronunciou-se :"E a mulher adquiriu um novo sentido, 'o sentido social'. Atravez da sociedade, Ella age hoje nos destinos da nação. Dentre os nossos problemas sociaes, porém, há um que se afigura básico. É o da assistência aos menores" (QUEIROZ, 1934, p.20).

2 Emenda $n^{\circ}$ 785: Pede a consignação de verbas especiais nos Orçamentos do Distrito Federal, dos territórios e dos municípios para assistência aos menores abandonados até 12 anos de idade, auxílio às famílias numerosas e aos indigentes inválidos para o trabalho, e nos orçamentos

\footnotetext{
${ }^{2}$ Nas atuais Legislaturas, essas duas áreas (Saúde e Educação) se encontram tratadas por Comissões Permanente diferentes. A Comissão de Educação e Cultura - CEC e Comissão de Seguridade Social e Família-CSSF.

${ }^{3}$ Optou-se por resumir os assuntos da Emenda e não colocá-los integralmente por não serem objetos de discussão do trabalho
} 
estaduais e do Distrito Federal para os menores de 12 a 16 anos de idade, que se positivou como o artigo $6^{\circ} \S 2^{\circ}$ do texto constitucional de 1934

3 Emenda $n^{\circ}$ 1011: Relatora da bancada paulista - inclui a mulher no dever cívico de juramento à bandeira e proporciona a sua inclusão na cidadania.. Este dispositivo foi contemplado no artigo $163 \S^{\circ}$, da Constituição de 1934.

4 Emendas n 170 a 179: criam o Conselho Nacional de Educação e propõem o Plano Nacional de Educação, que se positivou no texto da Constituição de 1934 na forma do artigo 152.

5 Emenda de proteção à infância, acatada como o artigo 138 da Constituição de 1934.

Concluindo, a Constituição de 1934 contemplou a mulher nos seguintes dispositivos:

Art. 109 - O alistamento e o voto são obrigatórios para os homens e para as mulheres, quando estas exerçam função pública remunerada, sob as sanções e salvas as exceções que a lei determinar.

Art. 121 - A lei promoverá o amparo da produção e estabelecerá as condições do trabalho, na cidade e nos campos, tendo em vista a proteção social do trabalhador e os interesses econômicos do País.

d) proibição de trabalho a menores de 14 anos; de trabalho noturno a menores de 16 e em indústrias insalubres, a menores de 18 anos e a mulheres;

h) assistência médica e sanitária ao trabalhador e à gestante, assegurando a esta descanso antes e depois do parto, sem prejuízo do salário e do emprego, e instituição de previdência, mediante contribuição igual da União, do empregador e do empregado, a favor da velhice, da invalidez, da maternidade e nos casos de acidentes de trabalho ou de morte;

Art. 138 - Incumbe à União, aos Estados e aos Municípios, nos termos das leis respectivas:

c) amparar a maternidade e a infância;

Art. 163 - Todos os brasileiros são obrigados, na forma que a lei estabelecer, ao Serviço Militar e a outros encargos, necessários à defesa da Pátria, e, em caso de mobilização, serão aproveitados conforme as suas aptidões, quer nas forças armadas, quer nas organizações do interior. As mulheres ficam excetuadas do serviço militar.

$\S 1^{\circ}$ - Todo brasileiro é obrigado ao juramento à bandeira nacional, na forma e sob as penas da lei.

Art. 168 - Os cargos públicos são acessíveis a todos os brasileiros, sem distinção de sexo ou estado civil, observadas as condições que a lei estatuir.

Art. 170 - O Poder Legislativo votará o Estatuto dos Funcionários Públicos, obedecendo às seguintes normas, desde já em vigor: (Brasil, 1934).

\subsection{Assembleia Nacional Constituinte de 1987}

O Presidente José Sarney promulgou a Emenda Constitucional no 26, de 27 de novembro de 1985, a qual determinava que os membros da Câmara dos Deputados e do Senado Federal reunir-se-iam, unicameralmente, em Assembleia Nacional Constituinte - ANC, livre e 
soberana, no dia $1^{\circ}$ de fevereiro de 1987 , na sede do Congresso Nacional para debaterem os rumos de um novo Estado democrático para o país. A Assembleia Nacional Constituinte funcionou no período de $1^{\circ}$ de fevereiro de 1987 a 5 de outubro de 1988, data da promulgação do texto constitucional, sob a presidência do deputado Ulysses Guimarães.

As mulheres tiveram participação ativa nesse processo histórico. Em 27 de março de 1987, entregaram ao Presidente a "Carta das Mulheres Brasileiras aos Constituintes", que contemplava as principais reivindicações, reunidas em ampla discussão nacional, coordenada pelo Conselho Nacional dos Direitos da Mulher, representado por sua presidente Jacqueline Pitanguy (Piovesan, 2008).

A mulher teve uma comissão para discutir os seus direitos a Comissão da Soberania e dos Direitos e Garantias do Homem e da Mulher. Dela faziam parte a deputada Anna Maria Rattes (PSDB/RJ), como vice-presidente, apoiada pela participação das parlamentares Lúcia Vânia (PMDB/RJ) e Dirce Quadros (PSDB/SP). A Assembleia Nacional Constituinte contou com a participação de 26 deputadas e nenhuma senadora entre os 590 parlamentares.

Abaixo são relacionadas as áreas temáticas de suas atuações: ${ }^{4}$

\section{1 - ABIGAIL FEITOSA - MARIA ABIGAIL FREITAS FEITOSA - PSB/BA}

Atuou nas áreas da aposentadoria, natalidade, infância, menor, educação e creche na Subcomissão dos Direitos dos Trabalhadores e Servidores Públicos. Apresentou a emenda da licença gestante de 120 dias, que foi aprovada. Na Comissão de Ordem Social, apresentou a emenda sobre planejamento familiar e fertilidade, também aprovada. No total, apresentou 166 emendas e teve 29 aprovadas foi membro da Comissão de Sistematização.

\section{2 - ANNA MARIA MARTINS SCORZELLI RATTES - PSDB/RJ}

Atuou nas áreas de família, igualdade de direitos e proteção ao menor. Apresentou 468 emendas e teve 120 aprovadas. Foi segunda-vice-presidente da Comissão da Soberania e dos Direitos e Garantias do Homem e da Mulher e membro da Subcomissão dos Direitos Políticos, dos Direitos Coletivos e Garantias.

\section{3 - BENEDITA SOUZA DA SILVA - PT/RJ}

Atuou nas áreas de planejamento familiar, menor, educação, trabalho doméstico, igualdade de sexo, licença gestante. Apresentou 93 emendas e teve 25 aprovadas. Membro da Subcomissão dos Negros, Populações Indígenas, Deficientes e Minorias e da Comissão da Ordem Social. Suplente da Mesa da Assembleia Constituinte.

\footnotetext{
${ }^{4}$ Fonte: Congresso Nacional. Constituição 20 anos. Optou-se por citar a quantidade das emendas e não colocá-las integralmente por não serem estas objetos de discussão do trabalho.
} 


\section{4 - BETH AZIZE - ELIZABETE AZIZE - PSDB/AM}

Atuou nas áreas de educação, creche, mulher e apresentou a emenda para o estabelecimento de juízo especial para crimes contra a mulher, que foi rejeitada. Apresentou 43 emendas e teve 12 aprovadas. Membro da Subcomissão de Princípios Gerais, Intervenção do Estado, Regime da Propriedade do Subsolo e da Atividade Econômica e da Comissão da Ordem Econômica.

\section{5 - BETE MENDES - ELIZABETE MENDES DE OLIVEIRA- PMDB/SP}

Licenciou-se do mandato de deputada federal constituinte em 15 de março de 1987, para exercer o cargo de secretária da Cultura do Estado de São Paulo.

\section{6 - CRISTINA TAVARES - MARIA CRISTINA DE LIMA TAVARES}

\section{CORREIA - PDT/RJ}

Atuou nas áreas de planejamento familiar, educação, menor, aborto e família. Apresentou 227 emendas e teve 95 aprovadas. Membro da Subcomissão da Ciência e Tecnologia e da Comunicação, da Comissão da Família, Educação, Cultura e Esportes, da Ciência e Tecnologia da Comunicação e da Comissão de Sistematização.

\section{7 - DIRCE TUTU QUADROS - DIRCE MARIA DO VALLE QUADROS - PSDB/SP}

Atuou nas áreas de planejamento familiar, creche e defensoria pública. Apresentou 56 emendas e teve 9 aprovadas. Membro da Subcomissão dos Direitos e Garantias Individuais e da Comissão da Soberania e dos Direitos e Garantias do Homem e da Mulher.

\section{8 - EUNICE MICHILES - PFL/AM}

Atuou nas áreas do menor, creche, planejamento familiar, licença maternidade e família. Apresentou 193 emendas e teve 54 aprovadas. Membro da Subcomissão da Família, do Menor e do Idoso e da Comissão da Família, Educação, Cultura e Esportes, da Ciência e Tecnologia da Comunicação.

\section{9 - IRMA PASSONI - IRMA ROSSETTO PASSONI - PT/SP}

Atuou nas áreas de educação, habitação e família. Apresentou 226 emendas e teve 71 aprovadas. Membro da Subcomissão da Política Agrícola e Fundiária e da Reforma Agrária e da Comissão de Ordem Econômica. 


\section{0 - LÍDICE DA MATA - LÍDICE DA MATA E SOUZA - PcdoB/BA}

Atuou nas áreas de educação, tributação, planejamento familiar e menor. Apresentou 196 emendas e teve 32 aprovadas. Membro da Subcomissão do Sistema Eleitoral e Partidos Políticos e da Comissão da Organização Eleitoral, Partidária e Garantias das Instituições.

\section{1 - LÚCIA BRAGA - ANTÔNIA LÚCIA NAVARRO BRAGA - PFL/PB}

Atuou nas áreas de educação, trabalho rural, habitação, aposentadoria da mulher dona de casa, menor e creche. Apresentou 117 emendas e teve 32 aprovadas. Primeira vice-presidente da Subcomissão dos Direitos e Garantias Individuais e membro da Comissão da Soberania e dos Direitos e Garantias do Homem e da Mulher.

\section{2 - LÚCIA VÂNIA - LÚCIA VÂNIA ABRÃO COSTA - PMDB/GO}

Atuou nas áreas de planejamento familiar, família e violência doméstica. Apresentou 143 emendas e teve 48 aprovadas. Membro da Subcomissão dos Direitos e Garantias Individuais e membro da Comissão da Soberania e dos Direitos e Garantias do Homem e da Mulher.

\section{3 - MÁRCIA KUBITSCHEK - PMDB/DF}

Atuou nas áreas de educação e cultura. Apresentou 42 emendas e teve 17 aprovadas. Membro da Subcomissão da Família, do Menor e do Idoso e da Comissão da Família, Educação, Cultura e Esportes, da Ciência e Tecnologia da Comunicação.

\section{4 - MARIA DE LOURDES ABADIA - PSDB/DF}

Atuou nas áreas de saúde, meio ambiente e tributação. Apresentou 70 emendas e teve 21 aprovadas. Segunda vice-presidente da Subcomissão da Saúde, Seguridade e do Meio-Ambiente e membro da Comissão da Ordem Social.

\section{5 - MARIA LÚCIA MELLO DE ARAÚJO - PMDB/AC}

Atuou nas áreas de planejamento familiar, família e menor. Apresentou 11 emendas e teve 2 aprovadas. Membro da Subcomissão da Família, do Menor e do Idoso e da Comissão da Família, Educação, Cultura e Esportes, da Ciência e Tecnologia da Comunicação.

\section{6 - MARLUCE PINTO - MARIA MARLUCE MOREIRA PINTO - PTB/RR}

Atuou nas áreas de saúde da mulher, aborto e aposentadoria da dona de casa. Apresentou 53 emendas e teve 16 aprovadas. Membro da Subcomissão da União, Distrito Federal e Territórios e da Comissão da Organização do Estado. 


\section{7 - MOEMA SÃO THIAGO - MOEMA CORREIA SÃO THIAGO -}

\section{PSDB/CE}

Atuou nas áreas de planejamento familiar, saúde, creche, trabalho doméstico e educação. Apresentou 98 emendas e teve 30 aprovadas. Membro da Subcomissão de Garantia da Constituição, reformas e Emendas e da Comissão da Organização Eleitoral, Partidária e Garantias das Instituições.

\section{8 - MYRIAM PORTELLA - MYRIAM NOGUEIRA PORTELLA NUNES -}

\section{PSDB/PI}

Atuou nas áreas de isonomia salarial, igualdade jurídica entre os sexos e posse da terra a trabalhadora rural e servidor público. Apresentou 174 emendas e teve 53 aprovadas. Membro da Subcomissão da Questão Urbana e Transporte e da Comissão da Ordem Econômica.

\section{9 - RAQUEL CÂNDIDO E SILVA - PDT/RO}

Atuou nas áreas de educação, tributação, igualdade jurídica entre os sexos e posse da terra à trabalhadora rural. Apresentou 75 emendas e teve 23 aprovadas. Membro da Subcomissão de Princípios Gerais, Intervenção do Estado, Regime de Propriedade de Subsolo e da Atividade Econômica e da Comissão da Ordem Econômica.

\section{0 - RAQUEL CAPIBERIBE DA SILVA-PSB/AP}

Atuou nas áreas de educação, tributação, igualdade jurídica entre os sexos, licença gestante de 120 dias. Apresentou 133 emendas e teve 44 aprovadas. Membro da Subcomissão da Política Agrícola e Fundiária e da Reforma Agrária e da Comissão de Ordem Econômica.

\section{1 - RITA CAMATA - RITA DE CÁSSIA PASTE CAMATA - PMDB/ES}

Atuou nas áreas de planejamento familiar, menor, família e educação. Apresentou 218 emendas e teve 66 aprovadas. Membro da Subcomissão da Família, do Menor e do Idoso e da Comissão da Família, Educação, Cultura e Esportes, da Ciência e Tecnologia da Comunicação.

\section{2 - RITA FURTADO - RITA ISABEL GOMES FURTADO - PFL/RO}

Atuou nas áreas de cultura e informação. Apresentou 66 emendas e teve 19 aprovadas. Membro da Subcomissão da Família, do Menor e do Idoso e da Comissão da Família, Educação, Cultura e Esportes, da Ciência e Tecnologia da Comunicação. 


\section{3 - ROSE DE FREITAS - PSDB/ES}

Atuou nas áreas de meio ambiente, trabalho, educação e menor. Apresentou 87 emendas e teve 13 aprovadas. Membro da Subcomissão do Sistema Financeiro e da Comissão do Sistema Tributário, Orçamento e Finanças.

\section{4 - SADIE RODRIGUES HAUACHE - PFL/AM}

Atuou nas áreas de educação, trabalho, família e licença gestante de 120 dias. Apresentou 132 emendas e teve 52 aprovadas. Membro da Subcomissão da Defesa do Estado, da Sociedade e de Segurança e da Comissão de Organização Eleitoral, Partidária e Garantias das Instituições.

\section{5 - SANDRA CAVALCANTI - SANDRA MARTINS CAVALCANTI - PFL/RJ}

Atuou nas áreas de educação, menor, família e licença gestante de 120 dias. Apresentou 214 emendas e teve 64 aprovadas. Membro da Comissão de Sistematização.

\section{6 - WILMA MARIA - WILMA MARIA DE FARIA MAIA - PDT/RN}

Atuou nas áreas de educação, trabalho, licença gestante de 120 dias e planejamento familiar. Apresentou 82 emendas e teve 26 aprovadas. Membro da Subcomissão dos Direitos dos Trabalhadores e Servidores Públicos e da Comissão da Ordem Social.

Quadro 1 - Mostra a distribuição partidária das parlamentares na ANC/1987:

\begin{tabular}{|c|l|c|}
\hline PARTIDO & \multicolumn{1}{|c|}{ ESTADO } & No DE DEPUTADAS \\
\hline PcdoB & Bahia & 1 \\
\hline PDT & Pernambuco, Rio Grande do Norte, Rondônia & 3 \\
\hline PFL & Amazonas, ** Paraíba, Rio de Janeiro, Rondônia & 5 \\
\hline PMDB & Acre, Distrito Federal, Goiás, Espírito Santo, São Paulo & 5 \\
\hline PSB & Amapá, Bahia & 2 \\
\hline PSDB & $\begin{array}{l}\text { Amazonas, Ceará, Distrito Federal, Espírito Santo, } \\
\text { Piauí, Rio de Janeiro e São Paulo }\end{array}$ & 7 \\
\hline PT & Rio de Janeiro, São Paulo & 2 \\
\hline PTB & Roraima & 1 \\
\hline * Amazte: Congresso Nacional. Constituição 20 anos. & \\
\hline Amas elegeu duas deputadas para ANC/1987 & \\
\hline
\end{tabular}

Nesse cenário político, constata-se que as 5 eleitas pelo PMDB são consideradas à esquerda do espectro político, e que, somando às do PT, às do PSB, PCdoB e do PTB, totalizaram 11 mulheres de posições mais progressistas. As 15 restantes sustentaram posições políticas conservadoras. 
Com relação à representatividade feminina por Estado, podemos observar que houve uma concentração nas regiões Sudeste e Nordeste que conseguiram eleger sete deputadas constituintes, enquanto que a região Sul não marcou presença.

Podemos observar vários dispositivos que contemplam a causa feminina na Carta Magna, no que preconiza:

Art. $3^{\circ}$ Constituem objetivos fundamentais da República Federativa do Brasil:

I - construir uma sociedade livre, justa e solidária;

II - garantir o desenvolvimento nacional;

III - erradicar a pobreza e a marginalização e reduzir as desigualdades sociais e regionais;

IV - promover o bem de todos, sem preconceitos de origem, raça, sexo, cor, idade e quaisquer outras formas de discriminação.

Art. $5^{\circ}$ Todos são iguais perante a lei, sem distinção de qualquer natureza, garantindo-se aos brasileiros e aos estrangeiros residentes no País a inviolabilidade do direito à vida, à liberdade, à igualdade, à segurança e à propriedade, nos termos seguintes:

I - homens e mulheres são iguais em direitos e obrigações, nos termos desta Constituição;

Art. $7^{\circ}$ São direitos dos trabalhadores urbanos e rurais, além de outros que visem à melhoria de sua condição social:

XX - proteção do mercado de trabalho da mulher, mediante incentivos específicos, nos termos da lei;

Art. 226. A família, base da sociedade, tem especial proteção do Estado.

$\S 5^{\circ}$ Os direitos e deveres referentes à sociedade conjugal são exercidos igualmente pelo homem e pela mulher. (Brasil, 1988)

\section{Conquistas}

No período democrático, pós-Constituição de 1988, floresce a normatização dos direitos femininos. Há, assim, a Lei $n^{\circ}$ 9029/95, que proíbe a exigência de atestados de gravidez e esterilização e outras práticas discriminatórias para efeitos admissionais ou de permanência da relação jurídica de trabalho; a Lei n. ${ }^{\circ}$ 10.224/2001, que dispõe sobre o crime de assédio sexual; e, por último, a Lei n. ${ }^{\circ} 11.340 / 2006$, que cria mecanismos para coibir e prevenir a violência doméstica e familiar contra a mulher, nos termos do $\S 8^{\underline{0}}$ do art. 226 da Constituição Federal, da Convenção sobre a Eliminação de Todas as Formas de Violência contra a Mulher, da Convenção Interamericana para Prevenir, Punir e Erradicar a Violência contra a Mulher e de outros tratados internacionais ratificados pela República Federativa do Brasil; e estabelece medidas de assistência e proteção às mulheres em situação de violência doméstica e familiar. Uma norma em especial é destacada - a Lei n. ${ }^{\circ}$ 9.504/97, "que dispõe 
sobre as normas para eleições", estabeleceu no seu artigo décimo que os partidos ou coligações deveriam reservar o mínimo de $30 \%$ e máximo de $70 \%$ para as candidaturas de cada sexo, a chamada Lei de Cotas (art.10).

Como resultado, o Tribunal Superior Eleitoral (TSE) divulgou que, em 1994 (ano anterior à legislação), o percentual de candidatas no Brasil era de 7,18\%; em 2002, esse número subiu para 14,84\%. Durante 60 anos, de 1932 até 1992, as brasileiras conseguiram obter no máximo 7\% das cadeiras do Legislativo municipal. Em 1994, elas representavam 8\% das Assembléias Legislativas do país e 6\% da Câmara dos Deputados.

Apesar da nova legislação, o crescimento de mulheres parlamentares tem ficado abaixo do esperado e do que acontece em outros países que adotaram algum tipo de política de cotas. Os resultados mostraram-se tímidos, o que revela a forma como a legislação foi adotada no país, ou seja, a legislação reserva $30 \%$ das vagas para cada sexo, mas não obriga que cada partido preencha as vagas destinadas ao sexo que tem representação minoritária. Portanto, nenhum partido cumpriu a cota de $30 \%$ na média nacional nas últimas eleições.

Dados do TSE revelam que, nas eleições municipais de 2004, a média nacional de candidaturas femininas para as câmaras Municipais foi de $22 \%$ e o percentual de vereadoras foi de $12 \%$. Essa ação afirmativa não resultou em um apoio efetivo e adequado às candidaturas femininas. Os partidos políticos não se comprometeram com o sistema de cotas e seus fundos não destinaram recursos de caráter afirmativo às candidaturas femininas.

Outro texto normativo que trouxe inovações à condição feminina na esfera pública foi o Novo Código Civil, a Lei $n^{\circ} 10.406$, de 10/1/2002, que introduziu avanços significativos referentes à proteção dos direitos civis da mulher, sob a perspectiva da igualdade entre os gêneros. Ele exclui da norma jurídica a chefia masculina da sociedade conjugal, o pátrio poder e a administração dos bens do casal pelo marido, inclusive dos particulares da mulher, a anulação do casamento pelo homem por motivo do conhecimento da defloração da mulher antes do matrimônio e a deserdação da filha desonesta que viva às expensas paternas. Também introduziu o poder familiar compartilhado; permitiu ao homem adotar o sobrenome da mulher e estabeleceu que a guarda dos filhos passa a ser do cônjuge com as melhores condições para exercê-la. O Novo Código Civil representa um grande avanço, especialmente no que diz respeito à proteção dos direitos civis das mulheres, sob a perspectiva da igualdade entre os gêneros.

No entanto, a despeito dos avanços jurídicos, os dados da realidade brasileira mostram que existe uma enorme distância entre as conquistas legais e as práticas sociais. Na política, as mulheres sofrem com a experiência de conciliar a vida privada com a pública. São depoimentos pessoais que retratam a realidade da dicotomia público x privado:

As mulheres casadas sabem como é difícil a política. É muito mais fácil ser solteira, não ter marido. Os maridos exigem. Meu marido, quando eu chegava em casa, dizia assim: "Eu sou a fêmea, você é o macho. Estou aqui como a 
fêmea te esperando. São 10 horas da noite, e você não chega. É assim, eles não aceitam - Prefeita Wilma de Farias - PSB/Natal/RN. (Grossi, 2001, p.184).

Outro ponto destacado pelas mulheres legisladoras é a falta de referência para as mulheres eleitas. Elas são tratadas como homens quando eleitas, são tratadas pelo gênero masculino. Isso se deve ao fato recente de sua entrada na esfera política. Um exemplo disso foi a inexistência de diplomas e carteiras com os cargos eletivos no feminino, demonstrando que a falta de apenas uma letra "a" pode significar muito no reconhecimento dessas novas mulheres.

A deputada federal Luiza Erundina (PSB/SP), integrante da bancada feminina da Câmara, considera que é preciso aumentar mais a participação da mulher na política brasileira. "O ritmo é pequeno. Para melhorar, os partidos políticos devem contribuir para a capacitação política das mulheres, para que elas tenham melhores condições de disputar eleições" (Agência Câmara, 2008).

A baixa representação contrasta com a composição do eleitorado brasileiro. Dos 130.5 milhões de cidadãos inscritos na Justiça Eleitoral, 51,8\% são mulheres (67.483.419). Isso significa que apenas $12 \%$ de mulheres são representantes nas câmaras de vereadores. A falta de representatividade feminina ocorre também na Câmara dos Deputados, que tem cerca de $10 \%$ de mulheres em sua composição. Na Câmara dos Deputados, nunca uma mulher foi membro efetivo da Mesa Diretora, fato que reforça a baixa representação da mulher no Poder Legislativo. Nota-se que o processo de distribuição do poder político entre homens e mulheres não é igualitário.

De acordo com o Índice de Equidade de Gênero (IEG) divulgado anualmente pelo Programa das Nações Unidas para o Desenvolvimento (PNUD, 2008) em seu relatório de desenvolvimento humano 2007/2008, o Brasil está no septuagésimo lugar no que se refere aos indicadores de desigualdades entre os sexos na participação política. Em 1999, o Brasil ocupava o septuagésimo nono lugar o que constata que houve progresso na participação política das mulheres, porém uma percentagem inexpressiva em nível mundial. O Brasil ainda ocupa uma posição desfavorável em relação a outros países da América Latina, tais como Argentina que ocupa o trigésimo oitavo lugar, Chile está no quadragésimo lugar e Uruguai com a quadragésima sexta posição. Sendo o país uma democracia, isso se contradiz com um dos princípios do regime democrático: a igualdade entre os indivíduos.

\section{Conclusão}

Em relação à categoria política, a mulher aumentou efetivamente sua representatividade em números no Parlamento: em 1933, contava com uma deputada; em 1987 registrou-se um número de 26 constituintes; a atual legislatura, $53^{\mathrm{a}}$ Legislatura - $2^{\mathrm{a}}$ Sessão Legislativa Ordinária 2009-2010 registra 44 mulheres eleitas na Câmara dos Deputados. A despeito da participação feminina no parlamento brasileiro vir se mostrando crescente desde a década de 1930, período 
inicial analisados pelo presente estudo, conclui-se que a quantia de deputadas federais que hoje se registra no parlamento brasileiro é ainda insuficiente. Trata-se de um quantitativo que não legitima o eleitorado feminino em relação à sua representatividade. Os mandatos, em número, estão muito aquém do que a sociedade necessita para atender às demandas das mulheres. No Brasil atual, faz-se imprescindível e vital a ampliação da efetiva participação das mulheres na política não apenas como eleitoras, defendendo a sua cidadania pelo direito de voto, mas, principalmente, como ocupantes eleitas de todos os cargos em âmbito nacional, estadual e municipal.

\section{Referências}

AGÊNCIA CÂMARA DOS DEPUTADOS. Cresce número de prefeitas, mas mulheres ainda são minoria. Brasília: Agência Câmara dos Deputados. 07 de out. 2008. Disponível em:http://www.camara.gov.br/homeagencia/materias.html . Acesso em: 07 out. 2008.

BOUDON, Raymond , FRANÇOIS, Bourricaud. Dicionário crítico de sociologia. São Paulo: Àtica, $1973.680 \mathrm{p}$.

BRASIL. Constituição Política do Império do Brasil (1824). Coleção das Leis do Brasil, Rio de Janeiro, v., p.7, 1824.

BRASIL. Constituição da República dos Estados Unidos do Brasil (1891). . Rio de Janeiro: Câmara dos Deputados, 1984. 26 p.

BRASIL. Constituição da República dos Estados Unidos do Brasil (1934). . Rio de Janeiro: Câmara dos Deputados, 1934. 35 p.

BRASIL. Constituição da República Federativa do Brasil (1988). 27.ed. Brasília: Câmara dos Deputados, Coordenação de Publicação, 2007. 88 p.

DIÁRIO DO PODER LEGISLATIVO. Rio de Janeiro: Imprensa Nacional, 1910-1937.

GODINHO, Wanor R.; ANDRADE, Oswaldo S. Constituinte Brasileiro de 1934. Rio de Janeiro: s.n, 1934. 304 p.

GROSSI, Miriam Pillar, Miguel, Sônia Malheiros. Transformando a diferença: as mulheres na política. Estudos Feministas. ano 9., n.1, p. 167-206.,2001

NAÇÕES UNIDAS. PNUD : relatório de desenvolvimento humano 2007/2008. São Paulo: IPAD, 2008. $520 \mathrm{p}$.

PIOVESAN, Flávia. $O$ Progresso das mulheres no Brasil. Disponível em: <http://www.mulheresnobrasil.org.br/pdt/PMB.Cap2.> Acesso em 30 de set. 2008.

QUEIROZ, Carlota Pereira de. Discursos pronunciados na Assembleia Nacional Constituinte de 1934, pela primeira deputada brasileira Carlota Pereira de Queiroz, da bancada paulista. Rio de Janeiro: Oficinas Gráficas do "Jornal do Brasil", 1934. 47 p.

TAVOLARO, Sérgio B.F. Para repensar a sociologia política da cidadania moderna. Novos Estudos. Rio de Janeiro, 8.jul. p. 117-130, 2008.

TELES, Maria Amélia de Almeida. Breve história do feminismo no Brasil. São Paulo, Brasiliense, 2003. 179 p.

Artigo recebido em: 25/03/2010

Artigo aceito para publicação em: 06/05/2010 